\title{
Complete Androgen Insensitivity Syndrome with Sertoli Cell Adenoma: A Case Report and Review of Literature
}

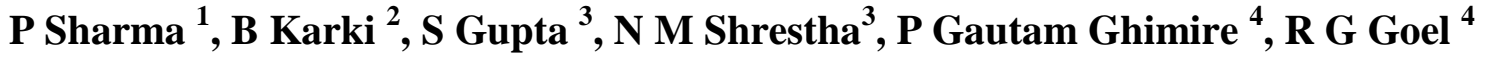

${ }^{1}$ Department of Radiology, Manipal Teaching Hospital, Pokhara, Nepal, ${ }^{2}$ Department of Surgery, ${ }^{3}$ Department of Urology, ${ }^{4}$ Department of Pathology Nepalgunj Medical College Teaching Hospital, Banke, Nepal.

\begin{abstract}
Complete androgen insensitivity syndrome is a rare X-linked recessive disorder. In patients with this syndrome, testicular tumors, especially seminoma, may develop after puberty Gonadal malignancies like sertoli cell tumor, yolk sac tumor; embryonic teratoma and unclassified sex cord stromal tumor are rare in these patients. We present here, a case of complete androgen insensitivity syndrome with sertoli cell adenoma in a 25 years old patient who presented to us with history of primary amenorrhoea and bilateral inguinal swellings and was managed with bilateral gonadectomy.
\end{abstract}

Keywords: Complete androgen insensitivity syndrome, Sertoli cell adenoma, Primary amenorrhoea.

\section{Introduction}

Complete androgen insensitivity syndrome (CAIS) also known as testicular feminizationsyndrome is one of the rare developmental abnormalities which results from the point mutations in both coding and gene $^{1}$. Clinically this condition is difficult to diagnose in childhood but suspicion should noncoding regions of the androgen receptor be raised when a female patient presents with primary amenorrhoea. The absolute risk of developing a testicular neoplasm in subjects with this syndrome is estimated to be $3.6 \%$ at the age of 25 years ${ }^{2}$. In patients with this syndrome, testicular neoplasms develop after puberty with seminoma being the most common histological type. Here we report a case of CAIS with unilateral sertoli cell adenoma.

Correspondence to: Dr. Prakash Sharma, MD, Department of Radiology and Imaging, Manipal Teaching Hospital, Pokhara, Nepal E mail: prakashshrm@yahoo.com

\section{Case Report}

A 21 years old female patient presented to the Nepalgunj Medical College Teaching Hospital with complaints of primary amenorrhoea. On examination, she was averagely built with minimal axillary and pubic hair. Bilateral breasts were small in size. Examination of genitalia revealed roomy, blind ended vagina. There were well defined, oval, mobile, firm, non tender swellings of about $4 \times 3 \mathrm{~cm}$ in the bilateral inguinal regions (Figure 1). She had luxuriant scalp hair without balding. Ultrasonography of the abdomen and pelvis revealed absence of uterus and bilateral ovaries (Figure 2). High resolution ultrasound of the inguinal region revealed well defined, oval lesion bilaterally. Echotexture of the lesions were like that of testis .Small $(5 \mathrm{~mm})$, well defined, hypoechoiec lesion was seen within the testis in the right inguinal region (Figure 3). CT of the pelvis also showed absence of the uterus 


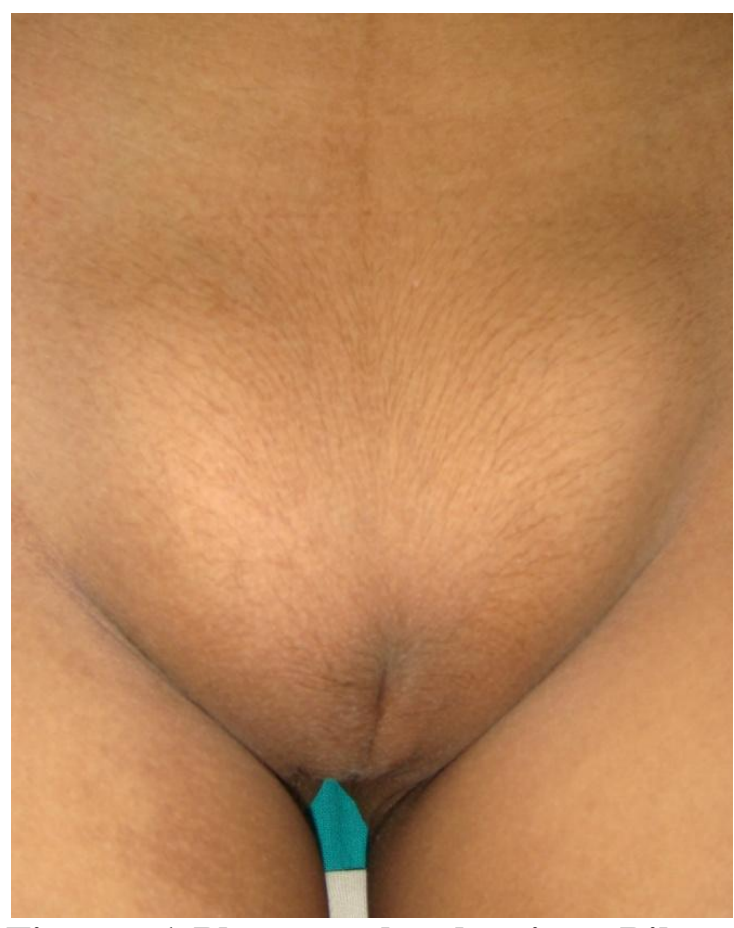

Figure 1:Photograph showing Bilateral inguinal swelling in a female.

with oval soft tissue density lesions in the bilateral inguinal region (Figure 4). Her karyotyping showed XY chromosome. After proper counseling, bilateral gonadectomy was done. Cut section of bilateral testes showed small well demarcated nodule in the lower pole of right testes (Figure 5).On histopathology both testis showed similar morphology. Seminiferous tubules were small and largely composed of immature sertoli cells and stray spermatogonia. There was marked leydig cell hyperplasia, one larger demarcated nodular focus was seen in

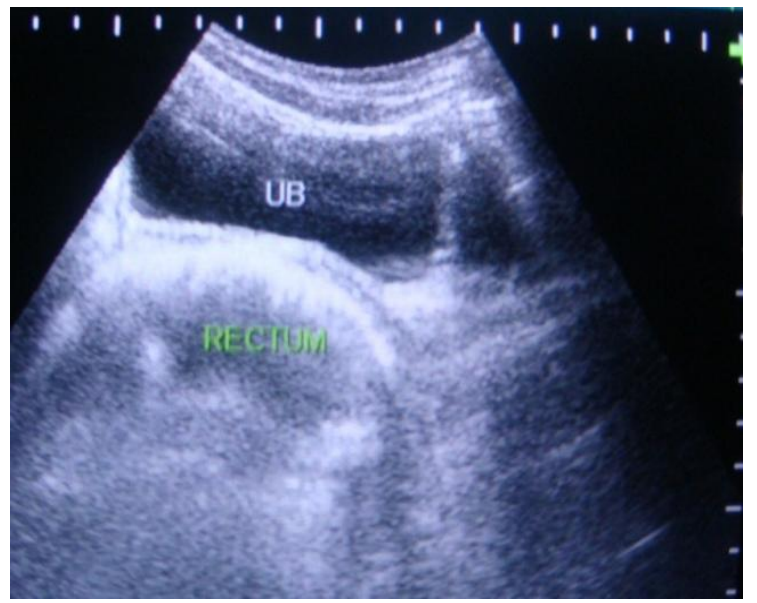

Figure 2: Ultrasound pelvis showing absence of uterus.

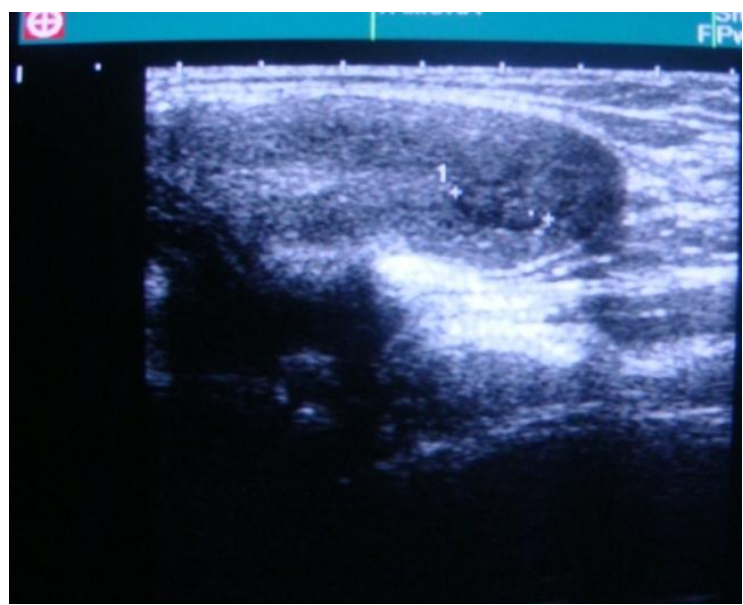

Figure 3: High resolution ultrasound of Right inguinal region showing oval, welldefined hypoechoiec lesion within the right testes.

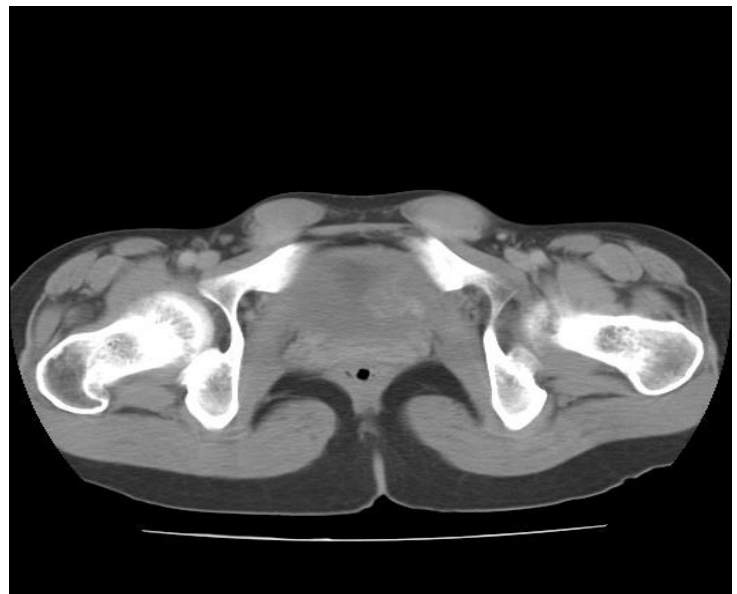

Fig 4: CT scan pelvis showing oval soft tissue in bilateral inguinal region with absence to uterus

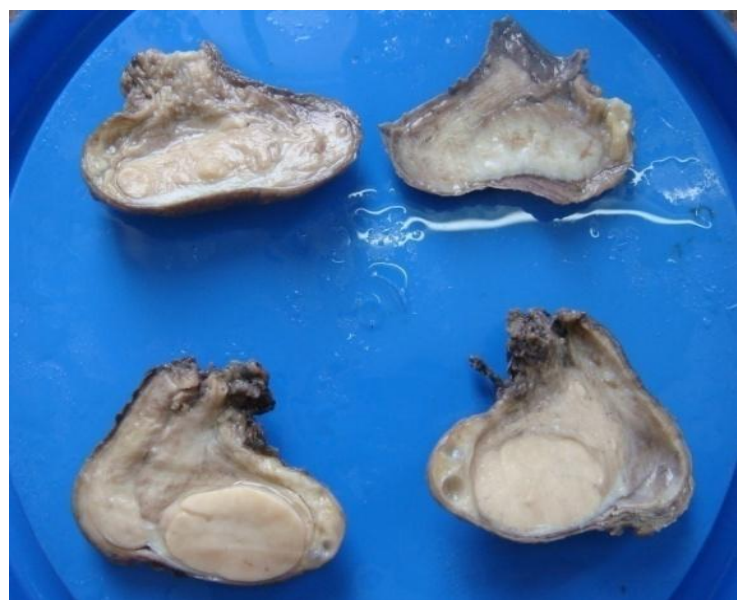

Figure 5: Cut section of bilateral testes (Upper photograph - Right testes showing small, oval, well-circumscribed lesion near the lower pole) 


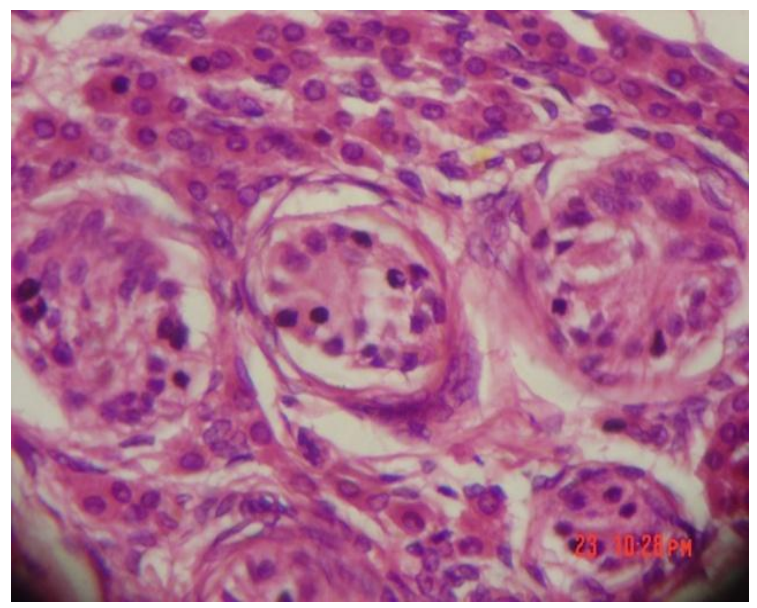

Figure 6: Histopathological examination of right testicular nodule showing sertoli cell adenoma.

the right testis and is composed of small tubules populated mostly by immature sertoli cells and leydig cell in the stroma. These foci were referred to as sertoli cell adenoma (Figure 6). Marked fibrosis was seen at places heavily surrounding the tubules. After gonadectomy she was reared as female. The patient is still being followed up regularly and she has no complaints.

\section{Discussion}

Complete androgen insensitivity syndrome is characterized by phenotypic female with 46XY karyotype, presenting with primary amenorrhoea, adequate breast development and absence or scanty pubic hair or axillary hair. The vagina may be shorter than normal and ends blindly. This condition was first described by Morris as testicular feminization ${ }^{3}$.

In our condition all the criteria were met. Like in our case most of the cases are diagnosed in postpubertal stage due to the primary amenorrhoea. Sometimes inguinal hernia may be associated with the condition. But in our case, it was not seen.

The gene responsible for creating the AIS phenotype has been localized to the proximal, long arm of the X chromosome at Xq11-12. There are four functional subsections, and eight exons, within the $110-\mathrm{kDa}$ androgen receptor (AR) protein. Approximately $70 \%$ of AR mutations are $X$-linked recessive ${ }^{4}$. Knoke et al ${ }^{5}$ reported two siblings with CAIS, Sertoli cell tumors, and an A (870) E mutation of the AR gene. They suggested that the A (870)E mutation in the AR gene could be the cause of the development of Sertoli cell tumor.

Women with mullerian agenesis also presents with primary amenorrhoea but they have normally developed ovaries and pubic and axillary hair ${ }^{6}$.

Various locations of testes have been mentioned in patients with CAIS. One study showed that out of 52 patients with the complete androgen insensitivity syndrome diagnosed 35 (67\%) had abdominal, 16 had inguinal and 1 had labial testes ${ }^{7}$. In our case, both the testes were present in the inguinal regions.

Magnetic Resonance Imaging (MRI) is considered as the gold standard investigation in cases of CAIS. But ultrasound abdomen and pelvis (USG) has got important role as the first line of investigation. USG can detect developmental abnormalities like absence of uterus and cervix and presence of testes in the abnormal location. High resolution USG can also detect intratesticular lesions like seminoma. Beside these findings, USG is also helpful in detecting congenital abnormalities of the renal system which may be associated with CAIS. In our case, due to the cost factor of MRI, only USG abdomen and pelvis was done which showed the above mentioned features without any renal abnormality ${ }^{8}$.

Complete androgen insensitivity syndrome is often associated with sertoli cell tumour. To the best of our knowledge till now 21 cases of sertoli cell tumour in patients of age-group 17-82 years associated with complete androgen insensitivity have been reported. Out of the 21 cases, 20 were reported to be of benign variety and one was advanced malignant disease . ${ }^{2}$ In our case, 
histopathology suggested benign lesion in the right testis.

The incidence of gonadal tumor (e.g.seminoma) is $3.6 \%$ and $33 \%$ at the age of 25 years and 50 years, respectively. Hence the recommended management is gonadectomy. It should not be performed before puberty because of its low risk of malignancy in pre-pubertal stage. Also it aids in the development of feminine secondary sexual characteristics 9 .

\section{Conclusion}

In conclusion, complete androgen insensitivity syndrome is a rare clinical entity. Occurrence of sertoli cell adenoma is still rarer. Gonadectomy should be done after puberty to prevent the risk of development of malignancy in the testes.

\section{References:}

1. Warner BW. Paediatric Surgery. In: Townsend CM, Beauchamp RD, Evers BM, Mattox KL editors. Sabiston Text Book of Surery. 18th ed. New Delhi: Elsevier 2008; 2072.

2. Wysocka B, Serkies K, Debniak J, Jassem J, Limon J. Sertoli Cell Tumor in Androgen Insensitivity Syndrome -A case Report. Gynecol Oncol 1999; 75: 480-483.
3. Morris J. The syndrome of testicular feminization in male pseudohermaphrodites. Am $J$ Obstet Gynec 1953;65: 1192- 1211.

4. Oakes MB, Eyvazzadeh AD, Quint E, Smith YR. Complete Androgen Insensitivity Syndrome-A Review. $J$ Pediatr Adolesc Gynecol 2008; 21:305310.

5. Knoke I, Jakubiczka S, Ottersen T, Goppinger A, Wieacker P. A(870)E mutation of the androgen receptor gene in a patient with complete androgen insensitivity syndrome and Sertoli cell tumor. Cancer Genet Cytogenet 1997; 98:139-41.

6. Frishman GN. Laparoscopic gonadectomy for androgen in sensitivity syndrome: karyotype tells the tale. Am J Obstet Gynecol 2007; 196:612.e1-612.e2

7. Barthold JS, Rivers KK, Upadhyay J, Shekarriz B ,McGinley JI. Testicular position in the androgen insensitivity syndrome: Implications for the role of androgens in testicular descent. The Journal of Urolocc 2000; 164: 497-501.

8. Moores P, Rashid M. A Case of Mistaken Identity: Complete Androgen Insensitivity Syndrome. Ultrasound 2009; 17: 153-155.

9. Yanai Y,Hiroi H,Osuga Y,Fujimoto A, Momoeda M,Hiroi $\mathrm{H}$ et al. Fertil and Steril 2008; 90;2018. 